\title{
Research on Applying Nano Cutting Oils in Spur Gear Hobbing Process
}

\author{
Tuan Ngo', Vi Hoang', Sinh Hoang ${ }^{2}$ \\ ${ }^{1}$ Faculty of Mechanical Engineering, Thai Nguyen University of Technology, Thai Nguyen, Vietnam \\ ${ }^{2}$ School of mechanical engineering, Hanoi University of Science and Technology, Hanoi, Vietnam \\ Email: minhtuanngo@tnut.edu.vn
}

How to cite this paper: Ngo, T., Hoang, V. and Hoang, S. (2017) Research on Applying Nano Cutting Oils in Spur Gear Hobbing Process. World Journal of Engineering and Technology, 5, 286-298. https://doi.org/10.4236/wjet.2017.52023

Received: April 28, 2017

Accepted: May 22, 2017

Published: May 25, 2017

Copyright ( 92017 by authors and Scientific Research Publishing Inc. This work is licensed under the Creative Commons Attribution International License (CC BY 4.0).

http://creativecommons.org/licenses/by/4.0/

\section{cc) (i) Open Access}

\begin{abstract}
Nanolubricant mixing the normal lubricant with nanoparticles, gradually becomes a new trend study for metal cutting enhancement. An addition of the nanoparticles improves lubricating properties and convective heat transfer coefficient (cooling properties) of nanolubricants. In the present work, nanolubricant is formulated by using dispersions of $0.3 \% \mathrm{Al}_{2} \mathrm{O}_{3}$ nanoparticles in normal industrial oil VG46 for enhancement of gear machining performance of SCM420 steel. Comparative study of flank wear, crater wear and gear profile error in gear hobbing with normal oils in the existing production line as well as nanolubricant is studied. This study clearly reveals that tool wear, and gear profile error are reduced by the use of nanolubricant compared to that of normal oils. The paper results not only contribute the deeper understanding of the novel performance of nanoparticles in conventional cutting fluids, but also show a very promising solution to achieve the engineering economy effectiveness in gear machining.
\end{abstract}

\section{Keywords}

Gear Hobbing, Cutting Fluid, Nanofluid, Nanolubricant, SCM420 Steel, $\mathrm{Al}_{2} \mathrm{O}_{3}$

\section{Introduction}

The spur gear is manufactured by the gear cutting process. The gear machining processes cause high levels of friction and wear on the cutting tool and high temperature as well. Those factors lead to the reduction of gear accuracy, surface quality and tool life, so using an appropriate cooling lubricant is very important. The earliest cooling lubrication application in gear cutting process is flood cooling, in which large amount of cutting fluid is poured as a continuous feed flow into contact area between the tool and workpiece. Cutting oil is a kind of cutting fluid, which is used in heavy duty cutting operations with low cutting speed (i.e., 
shaping, hobbing process). The excellent characteristic lubrication of cutting oil not only enables it to form an oil film on the workpiece surface and reduce frictional coefficient, cutting temperature and cutting forces, but also aids in lubricating, flushing away chips from the machining zone, and rust protection. The use of cutting oil in gear machining results in considerable application costs together with pollution and hazards to the environment and the human body. Due to the increasing in demand for enhancing machining productivity as well as machining accuracy, the extensive application of cutting oil in gear hobbing have been found in many industries. According to the significant performance of oil-based lubricants, there have been numerous studies conducted to enhance their efficiency. In recent years, the use of cooling lubricants comprising nanoparticles, such as $\mathrm{Al}_{2} \mathrm{O}_{3}$, WS2, MoS2 and so forth, called nanolubricant has attained much attention in the machining field. In Anuj Kumar Sharma's studies, three different nanofluids are prepared by mixing Titanium dioxide $\left(\mathrm{TiO}_{2}\right)$, Silicon oxide $\left(\mathrm{SiO}_{2}\right)$ and Aluminum oxide $\left(\mathrm{Al}_{2} \mathrm{O}_{3}\right)$ nanoparticles in vegetable oil-water emulsion at room temperature in different volumetric concentrations [1]. Further, based on the results in end milling obtained from the Taguchi optimization method, M. Sayuti reported that $\mathrm{SiO}_{2}$ nanolubrication exhibits the promising results as reducing cutting temperature as well as cutting forces, and improving surface finish [2]. RR Srikant concluded that thermal conductivity, heat transfer capacity and tool life were enhanced by using cutting fluids with an inclusion of $\mathrm{CuO}$ nanoparticles in MQL turning process [3]. Bizhan Rahmati et al investigated the optimum molybdenum disulfide (MoS2) nanolubrication parameters in CNC milling of AL6061-T6 alloy [4]. The results revealed that cutting force, cutting temperature and surface roughness can be minimized by applying nanoparticle suspended concentration in the mineral oil. Mohd Sayuti et al. studied nano suspended lubrication in precise machining of aerospace $\mathrm{AL}$ tempered grade 6061 [5]. The results indicate that using $\mathrm{SiO}_{2}$ nanoparticles in cutting oil facilitated by high pressure stream air reduces cutting force, improving surface roughness and increasing cutting temperature. Moreover, they also suggested that too large amounts of nanoparticles would lead to worse conditions due to collisions and impedance among the particles and asperities. Due to spherical morphology, Eastman JA suggested that the $\mathrm{Al}_{2} \mathrm{O}_{3}$ nanoparticles have not only the size and appropriate cost but also their superior tribological and anti-toxic properties suitable to add to the industrial oils [6]. S. Khalilpourazary and S. S. Meshkat studied the effects of alumina nanoparticles on spur gear surface roughness and hob tool wear in hobbing process [7]. They concluded that using nanolubricant with alumina nanoparticles resulted in decreasing surface roughness values $(\mathrm{Ra}, \mathrm{Rz})$ and tool wear in the manufactured spur gears. Ahmed A. D. Sarhan added $\mathrm{SiO}_{2}$ nanoparticles (0.2 wt. \%) having an average size of 5 $10 \mathrm{~nm}$ into the mineral oil and studied their effects on the coefficient of friction, cutting forces, specific energy, and power in milling [8]. The author found that reducing the coefficient of friction, cutting forces, specific energy and required power is achieved compared to the case of an ordinary lubrication system. 
According to conducted research on the use of nano lubricants for optimizing machining performance, little has been reported on the application of $\mathrm{Al}_{2} \mathrm{O}_{3}$ nanoparticles suspended in the ISO VG 46 oil for improving the gear hobbing performance of SCM420 steel. Therefore, this research attempts to investigate the performance of $\mathrm{Al}_{2} \mathrm{O}_{3}$ based nanolubrication in gear hobbing process of SCM 420 steel. The experimental results reveal that the tool wear, gear profile error, and surface roughness are decreased when compared with the case of using the ISO VG 46 industrial lubricant at the same cutting conditions.

\section{Material and Method}

\subsection{Experimental Devices}

Based on the existing gear production line, the experimental research aims to enhance the productivity and quality of machined spur gears with minimal additional costs. All the experiments were conducted on YBS3120 hobbing machine. The machined spur gears are used in gear boxes of motorbikes with the information shown in Table 1 . The requirement of accuracy grade is 9 (according to ISO 1328-2-1997). Hob tool was made from Dragon Precision Tools Co., Ltd with technical specification shown in Table 2. The cutting condition is listed in Table 3. Depending on the existing system in Machinery Spare Parts No.1 Joint Stock Company (FUTU1) in Vietnam, the industrial lubricant VG46 was used in gearing machining due to economic and technical characteristics. The experimental set up is shown in Figure 1.

The $\mathrm{Al}_{2} \mathrm{O}_{3}$ nanoparticles are made by US Research Nanomaterials, Inc. TEM image is shown in Figure 2 and the information is given in Table $4 . \mathrm{Al}_{2} \mathrm{O}_{3}$ na

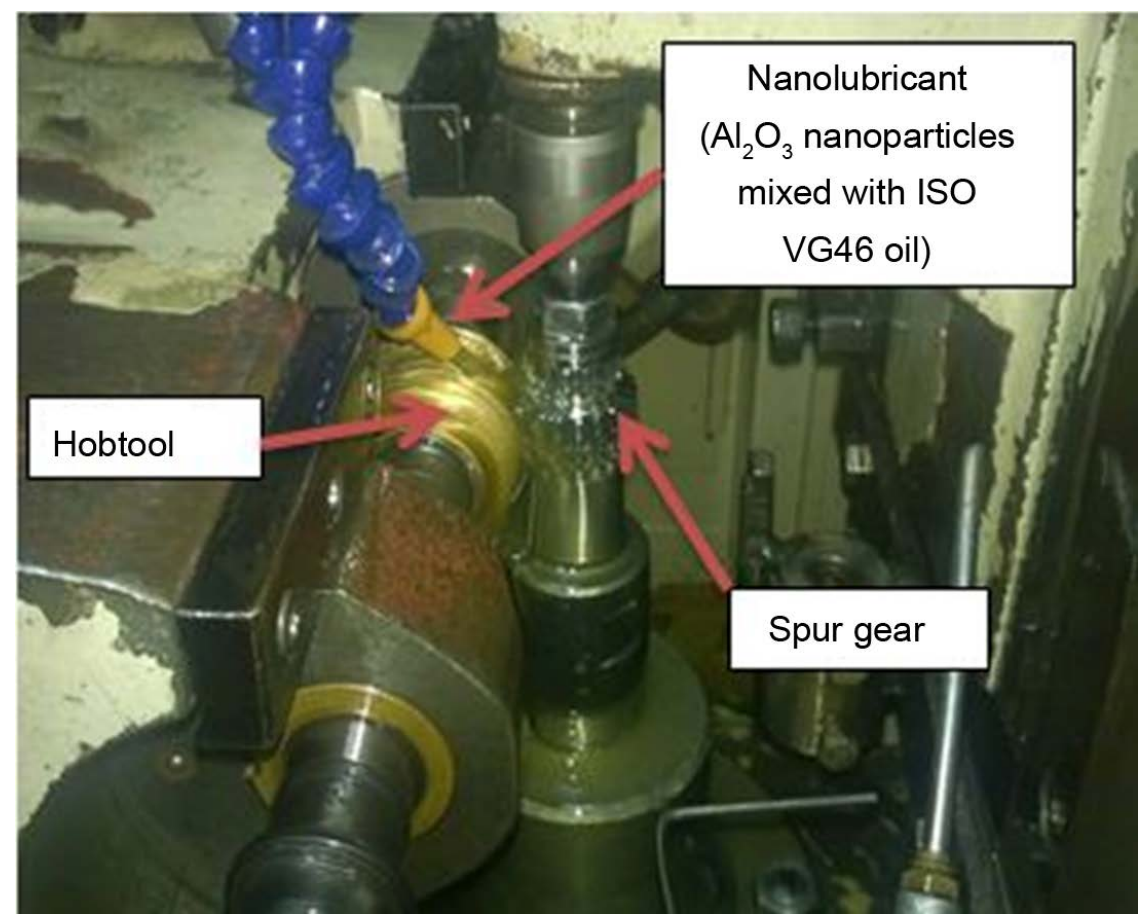

Figure 1. Manufacturing the spur gear with Nanolubricant in hobbing machine. 


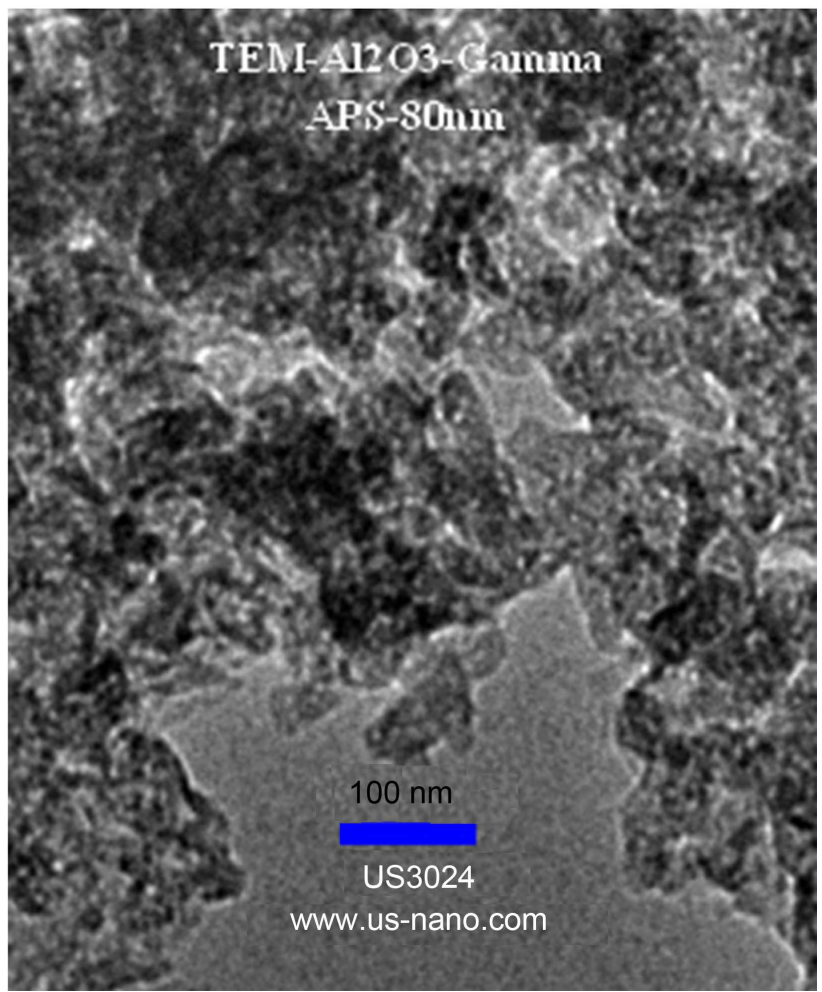

Figure 2. TEM image of $\mathrm{Al}_{2} \mathrm{O}_{3}$ nano particles (from US Research Nanomaterials, Inc.).

Table 1. Corresponding dimensions of the spur gear.

\begin{tabular}{cc}
\hline Parameters & Dimension \\
\hline Number of teeth & 21 \\
Pressure angel & $20^{\circ}$ \\
Module $(\mathrm{mm})$ & 1.75 \\
\hline
\end{tabular}

Table 2. Technical specification of the hob.

\begin{tabular}{cc}
\hline Technical specification & \\
\hline Company name & DTR \\
Accuracy grade & DIN-AA \\
Module $(\mathrm{mm})$ & 1.75 \\
Outside diameter $(\mathrm{mm})$ & 60 \\
Twist angle & $1^{\circ} 43^{\prime}$ \\
Number of flute & 12 \\
Material & SKH-55 \\
Coated material & TIN \\
\hline
\end{tabular}

noparticles with the size of $80 \mathrm{~nm}$ were selected according to the economical requirement. Alumina nanoparticles were mixed with normal oil VG46 (mineral based oil) following the weight ratio of $0.3 \%$ [5] in order to produce the nanolubricant. The mixing process is done by ultrasonic vibration. 
Table 3. Cutting condition.

\begin{tabular}{cc}
\hline Cutting parameter & \\
\hline Spindle speed (rev/min) & 200 \\
Depth of cut (mm) & 4.375 \\
Feed rate (mm/rev) & 1.27 \\
Milling method & conventional \\
\hline
\end{tabular}

Table 4. Characteristics of $\mathrm{Al}_{2} \mathrm{O}_{3}$ nanoparticles (from US Research Nanomaterials, Inc.).

\begin{tabular}{cc}
\hline Parameter & Value \\
\hline Color & White \\
Nanoparticles morphology & Nearly spherical \\
Particle average size $(\mathrm{nm})$ & 80 \\
Purity $(\%)$ & $\geq 99$ \\
Specific heat capacity $(\mathrm{J} / \mathrm{Kg} . \mathrm{K})$ & 880 \\
Density $\left(\mathrm{kg} / \mathrm{m}^{3}\right)$ & 3.890 \\
\hline
\end{tabular}

Machined gear profile was measured by the OSAKA SEIKI KIKAI gear measuring machine made by Japan (Figure 3). The flank wear and crater wear of hob tool was measured by Zeiss optical microscope (Figure 4). All the measuring processes were conducted in Measuring Centre in Machinery Spare Parts No.1 Joint Stock Company, Vietnam.

\subsection{Experiment}

The comparative study of machining performance between the normal oil and nanolubricant was carried out under the same cutting condition. In FUTU1, after about 500 gears were machined, the hob position will be changed, because the tool wear is large. Thus, the machining process was stopped the four times after the $50^{\text {th }}, 100^{\text {th }}, 200^{\text {th }}, 300^{\text {th }}$ and $400^{\text {th }}$ gears were machined, and the measuring processes of gears and hob tools were performed. The hob was continually used to machine until the 500 gears were completed.

\section{Result and Discussion}

\subsection{The Hob Wear}

The problem of hob wear is very complex but several considerations must be made on this matter since it has a direct impact on the final cost of the gear. There are two types of wear that occur on hob teeth, the flank wear and crater-type wear. Flank wear of hob tool with normal lubricant and nanolubricant was captured and measured by by Zeiss optical microscope after the $5^{\text {th }}, 50^{\text {th }}$, $100^{\text {th }}, 200^{\text {th }}, 300^{\text {th }}, 400^{\text {th }}$ and $500^{\text {th }}$ gears were machined, shown in Figures 5-11. The initiation of tool wear of the coated TiN hob is caused by chipping failure of the coating. In order to observe the initiation of tool wear, the flank faces of 


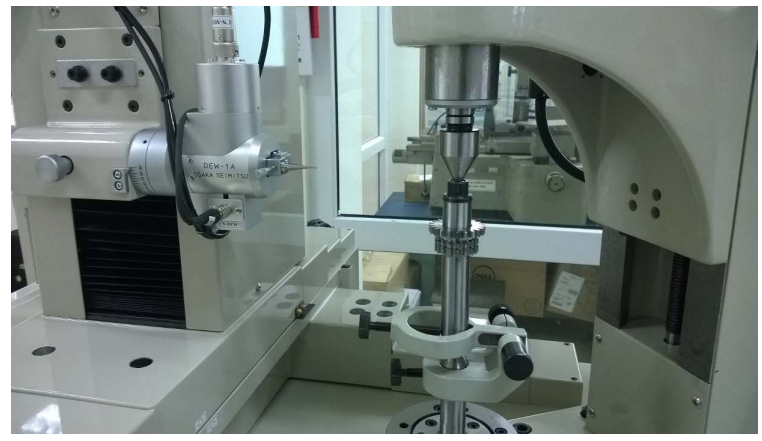

Figure 3. OSAKA SEIKI KIKAI gear measuring machine for gear profile error.

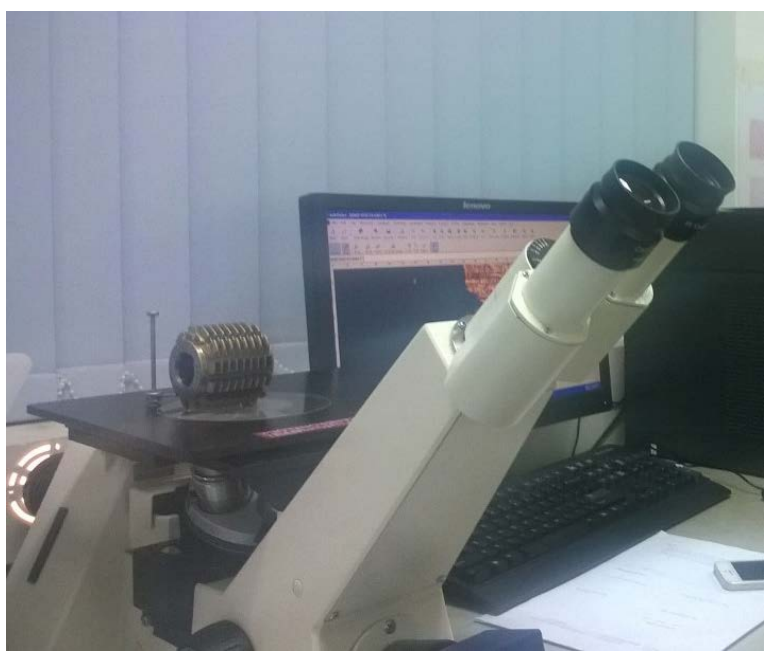

Figure 4. The wear of hob tool measured by Zeiss optical microscope.

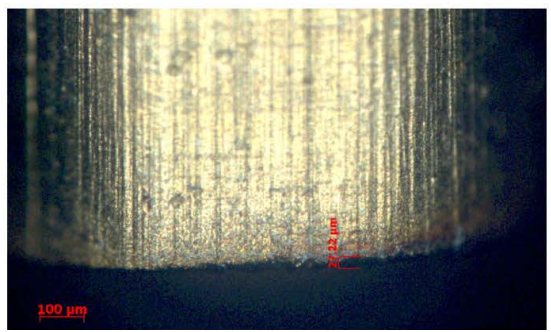

(a)

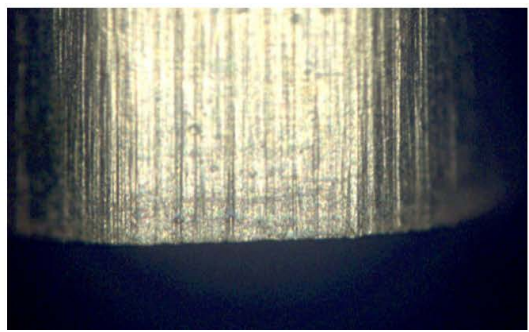

(b)

Figure 5. Flank wear after machining the $5^{\text {th }}$ gear using: (a) Normal lubricant $(27.22 \mu \mathrm{m})$; (b) Nanolubricant.

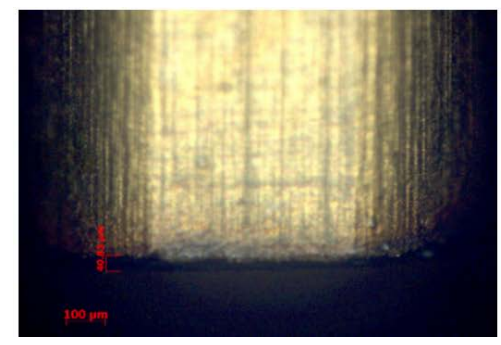

(a)

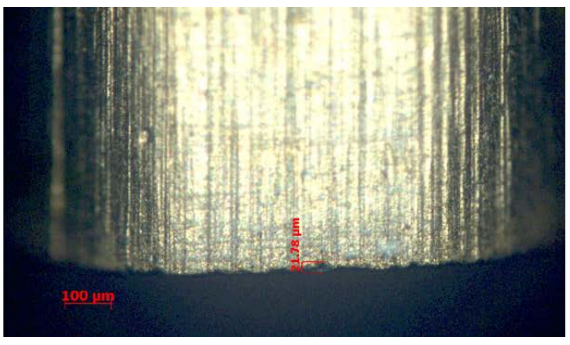

(b)

Figure 6. Flank wear after machining the $50^{\text {th }}$ gear using: (a) Normal lubricant $(40.83 \mu \mathrm{m})$; (b) Nanolubricant $(21.78 \mu \mathrm{m})$. 


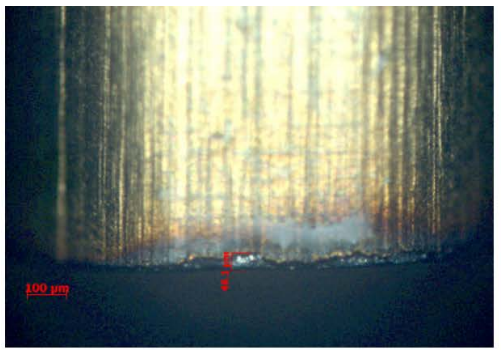

(a)

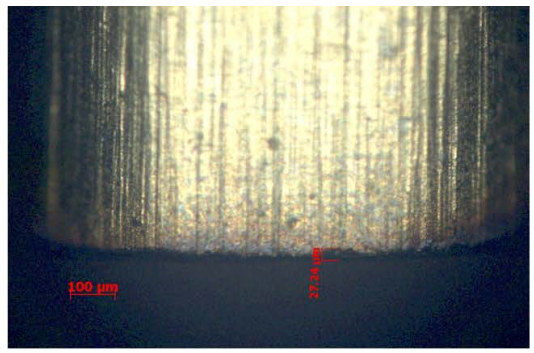

(b)

Figure 7. Flank wear after machining the $100^{\text {th }}$ gear using: (a) normal labricant $(48.1 \mu \mathrm{m})$; (b) VG46 nanolubricant $(27.24 \mu \mathrm{m})$.

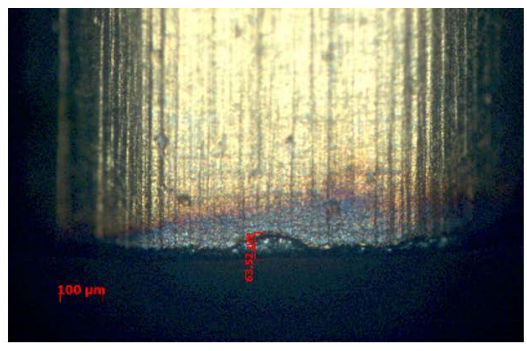

(a)

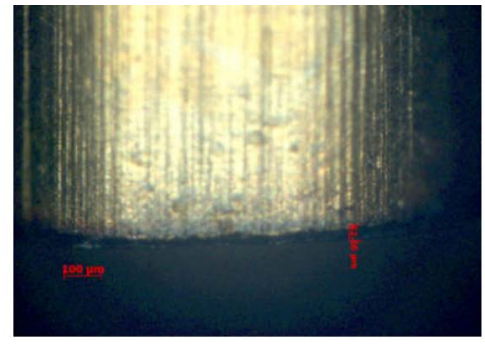

(b)

Figure 8. Flank wear after machining the $200^{\text {th }}$ gear using: (a) normal labricant $(63.52 \mu \mathrm{m})$; (b) VG46 nanolubricant $(42.66 \mu \mathrm{m})$.

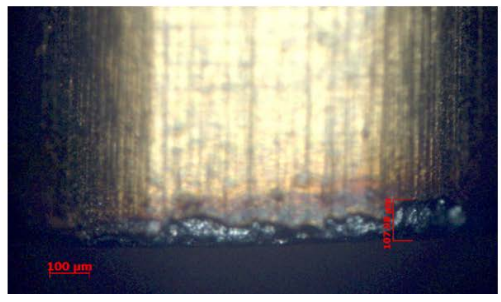

(a)

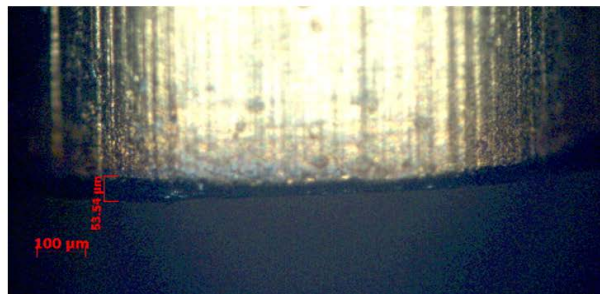

(b)

Figure 9. Flank wear after machining the $300^{\text {th }}$ gear using: (a) normal labricant $(107.98$ $\mu \mathrm{m})$; (b) VG46 nanolubricant $(53.54 \mu \mathrm{m})$.

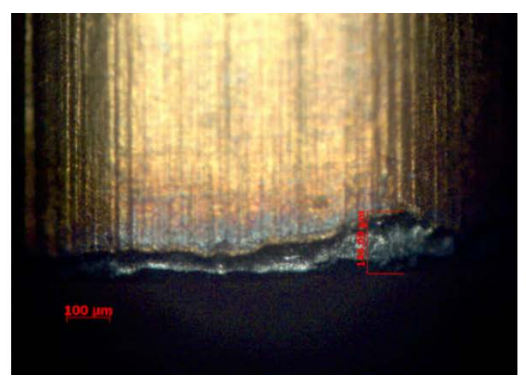

(a)

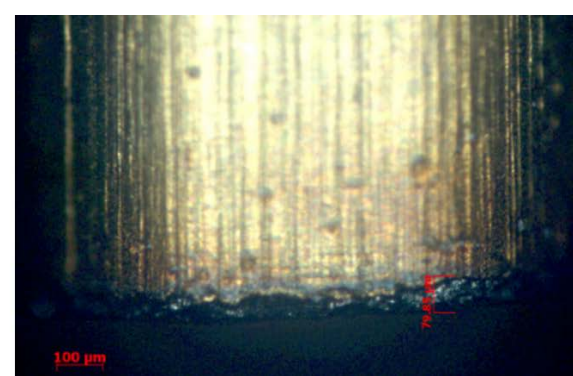

(b)

Figure 10. Flank wear after machining the $400^{\text {th }}$ gear using: (a) normal labricant $(146.09$ $\mu \mathrm{m})$; (b) VG46 nanolubricant $(79.85 \mu \mathrm{m})$.

samples after 5 gears (with normal lubricant) and 50 gears (with nano lubricant) were inspected, shown in Figure 5(a) and Figure 6(b)). After the TiN coating were cracked and stripped, the mechanism wears of the HSS material were de 


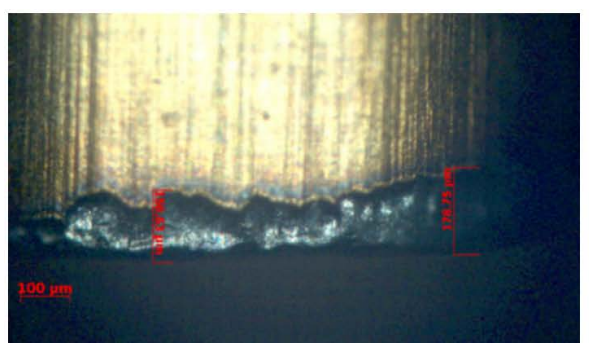

(a)

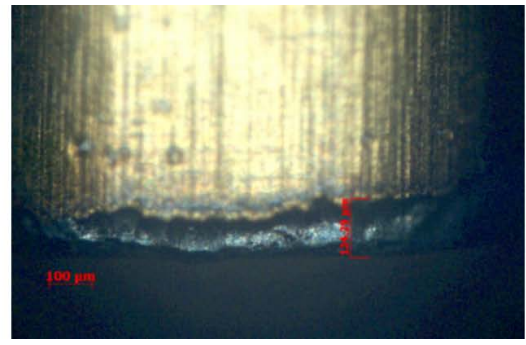

(b)

Figure 11. Flank wear after machining the $500^{\text {th }}$ gear using: (a) normal labricant $(178.75$ $\mu \mathrm{m})$; (b) VG46 nanolubricant $(134.29 \mu \mathrm{m})$.

tected, shown in Figures 6(a)-11(a) and Figures 7(b)-11(b). The Figure 5(a)-11(a) showed that the color of tool face was changed, because the cutting temperature was so high. It is believed that this is mainly an effect of higher temperatures being generated at the tool interface, resulting in a softening of the underlying high speed steel and the TiN coating has been cracked and subsequently depressed into the HSS material before being removed. This result indicated that the width of flank wear using normal lubricants increased faster than using nano lubricant during the machining process. It clearly reveals that the width of flank wear reduces about 24.87 (after machining 500 gears - 50.42\% (after machining 300 gears) under machining condition with nanolubricant compared to normal lubricant at the different stop times.

After 500 gears were machined, the crater wear of the rake surface of hob were taken by Zeiss optical microscope, shown in Figure 12 and Figure 13. The result revealed that portion of the TiN coating are removed from the rake face. The width of crater wear area under nanolubricant is clearly smaller than under normal lubricant. Hence, some dents can be found on the rake surface under normal oils, while nothing on the rake face under nano oils.

With detected the flank and crater wear, it can be explained that nanoparticles remained in oil mist plays an important role as billion balls in creating "roller effect". In cutting area, rolling friction instead of sliding one occurs between flank face and machined surface, rake face and chip surface, and so forth. Hence, the friction, cutting forces, tool wear are reduced. Although the cutting forces and cutting temperature during gear hobbing process are not included in this research, they can be evaluated through the color of flank wear from Figures 5-11. The width of wear land under nanolubricant is clearly smaller, but the color of the worn coating and substrate layer almost remains the same. In contrast, the width of wear land under normal lubricant is larger, and the color of the worn ones turns black due to high temperature generated from machining. It can be drawn that the novel characteristics of nanoparticles such as thermal conductivity, heat transfer capacity, and tribology enhance the cooling-lubricant performance of normal lubricant.

\subsection{Total Profile Errors of the Hobbed Gears}

There are many factors influencing the gear profile accuracy, but the experiment 

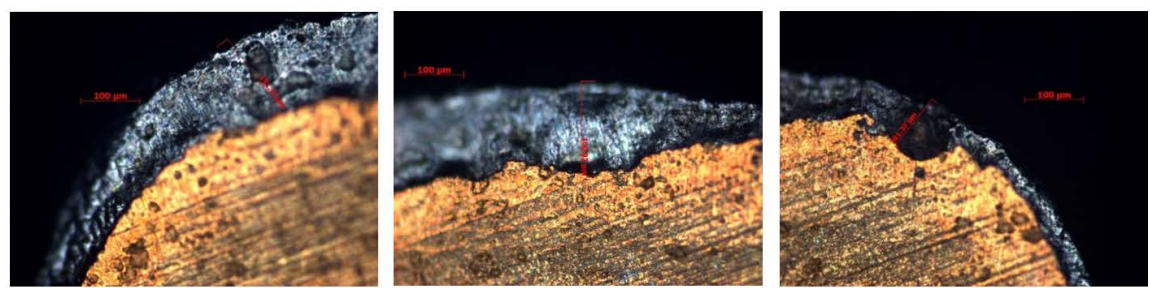

Figure 12. The crater wear of hob (right-151.13 $\mu \mathrm{m}$, center-160.92 $\mu \mathrm{m}$ and left-101.37 $\mu \mathrm{m}$ position on rake face) after machining 500 gears with normal lubricant.
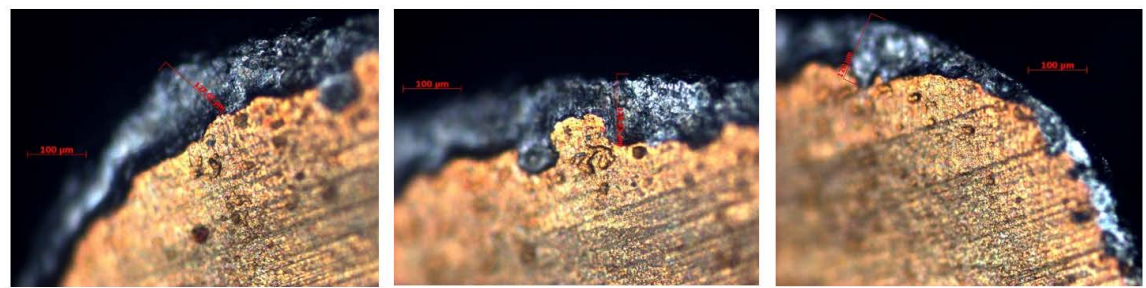

Figure 13. The crater wear of hob (right-127.07 $\mu \mathrm{m}$, center-126.33 $\mu \mathrm{m}$ and left-120 $\mu \mathrm{m}$ position on rake face) after machining 500 gears with nanolubricant.

was carried out in the same machine tool, cutting condition and hob. The only change is the normal lubricant replaced by the proposed nano lubricant added $0.3 \% \mathrm{Al}_{2} \mathrm{O}_{3} 80 \mathrm{~nm}$. The tooth profile errors of the hobbed gear have two main types, nearly sinusoidal shape and having the some dents in the profile, see Figure 14 and Figure 15. Recent studies have shown that the sinusoidal shape of the hobbed gear profile were mainly caused by the geometrical errors of the hob or machine and the run out of the hob during the cutting process. And, the hob errors or the hob wear causes the dents in the hobbed gear profile. In this paper, the same conditions were set in two experients and only focused on studying the influence of the hob wear to the profile errors. Figure 14 shows the tooth profile error of the hobbed gears using normal industrial oils. The results show that the tooth profile errors of the first 300 gears have the same shape at the all teeth and don't change but the total profile errors increase from the $400^{\text {th }}$ gear. Moreover, the profile of the $400^{\text {th }}$ and $500^{\text {th }}$ gears machined with normal oils are not smooth and have some dents. Figure 15 shows the tooth profile error of the hobbed gears using nanolubricants. The results indicated that the profile errors of hobbed gears using nano oils is smoother. The tooth profile errors of the first 400 gears have the same shape at the all teeth and don't change but the total profile errors increase from the $500^{\text {th }}$ gear. Hence, the higher gear profile accuracy is achieved in the case of nano lubricant. The reduction of tool wear is the main factor contributed to preserve the tool profile accuracy. In addition, the spherical morphology of nano particles takes part in the decrease of friction force and cutting temperature.

\section{Conclusions}

In this investigation, the VG46 nanolubricant effectively improves the cooling lubricant of gear hobbing process compared to the case of using the ISO VG 46 

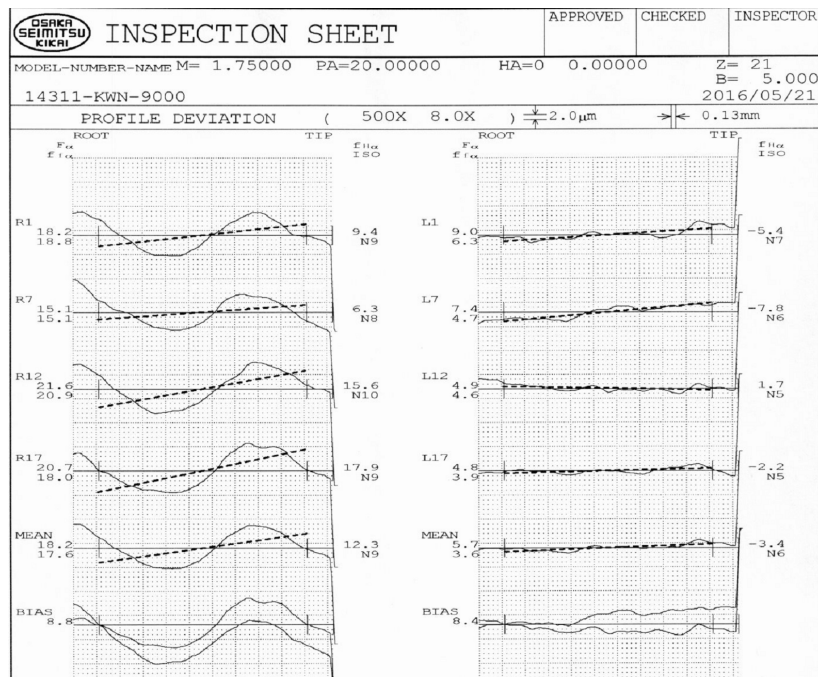

(a)
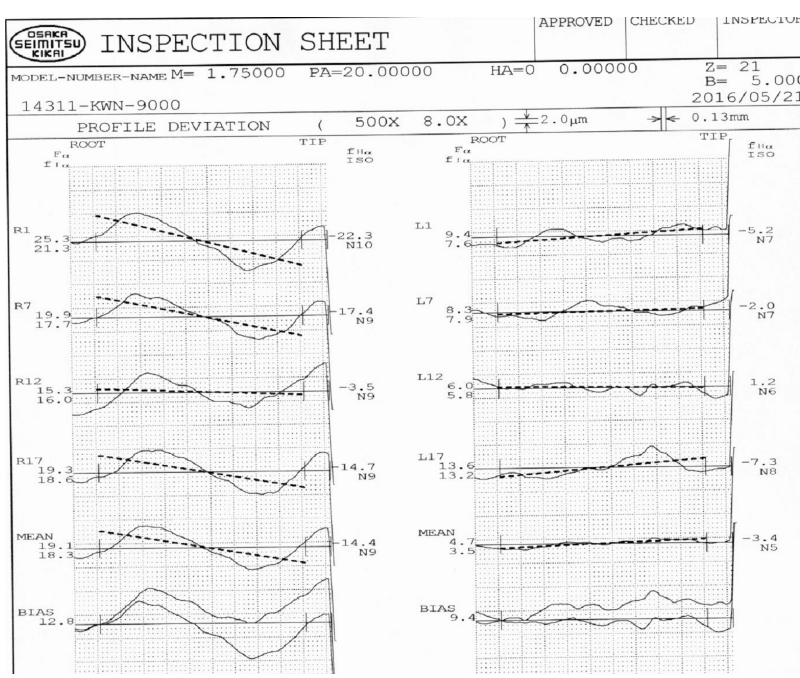

(c)
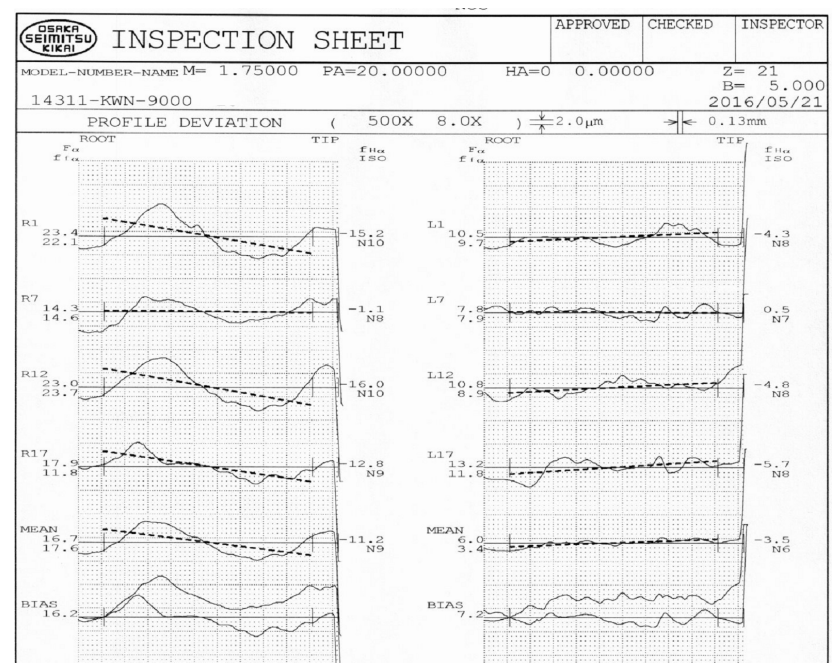

(e)

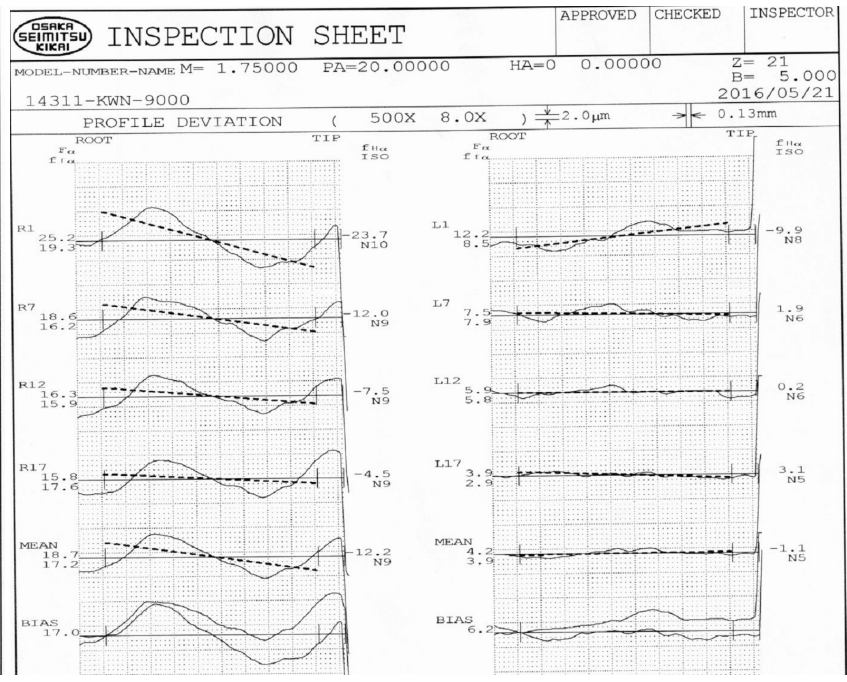

(b)

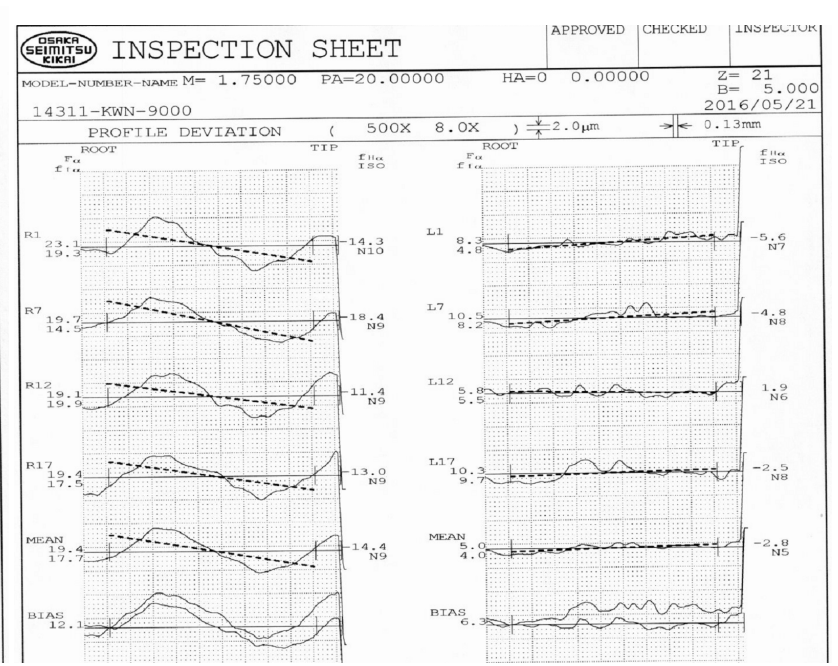

(d)

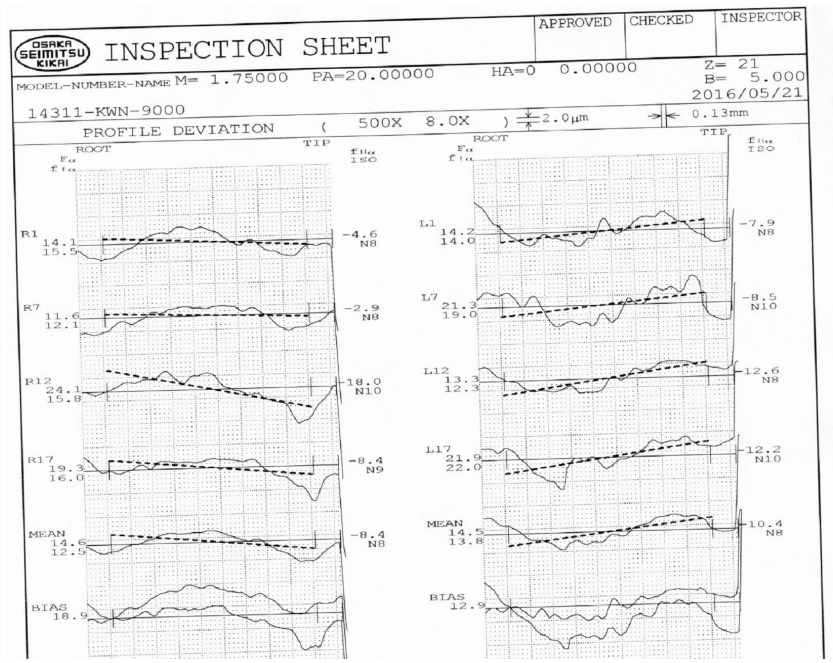

(f)

Figure 14. The profile error of the hobbed gear with normal lubricants. (a) The $50^{\text {th }}$ gear; (b) The $100^{\text {th }}$ gear; (c) The $200^{\text {th }}$ gear; (d) The $300^{\text {th }}$ gear; (e) The $400^{\text {th }}$ gear; (f) The $500^{\text {th }}$ gear. 


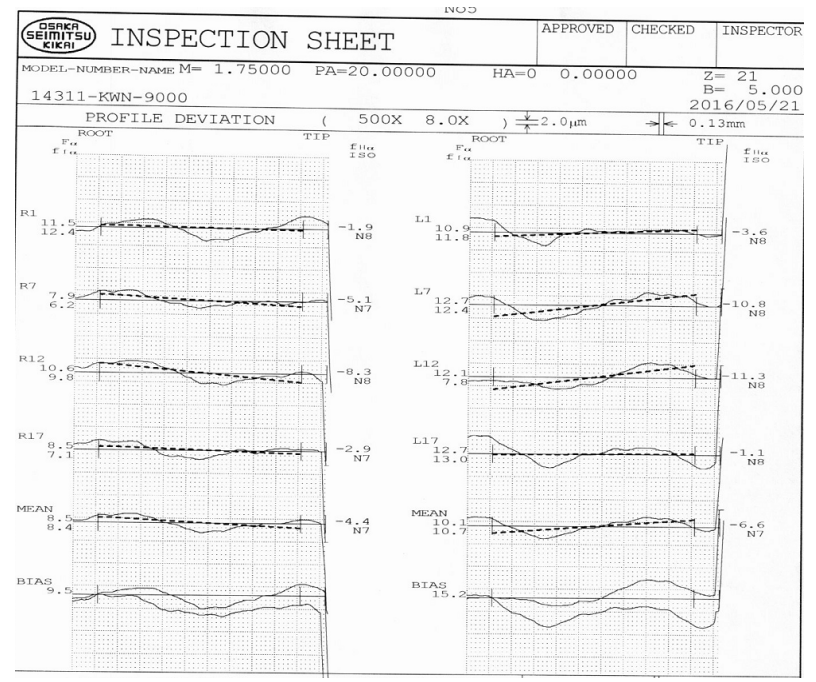

(a)

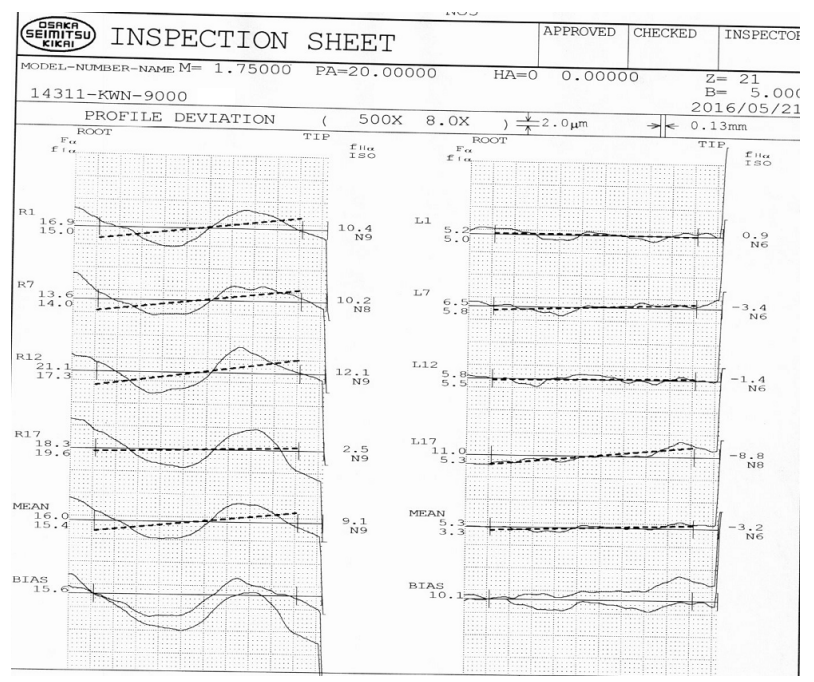

(c)

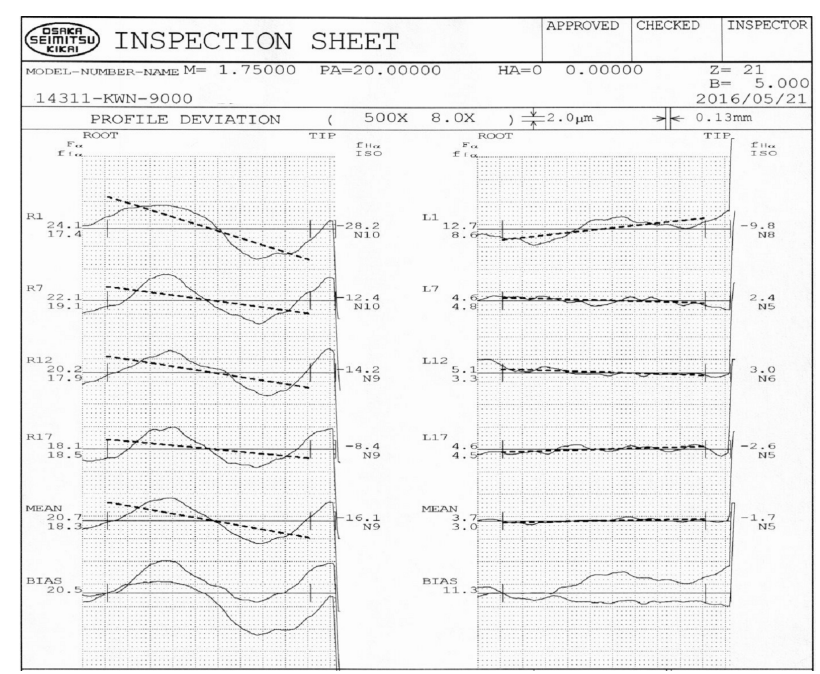

(e)

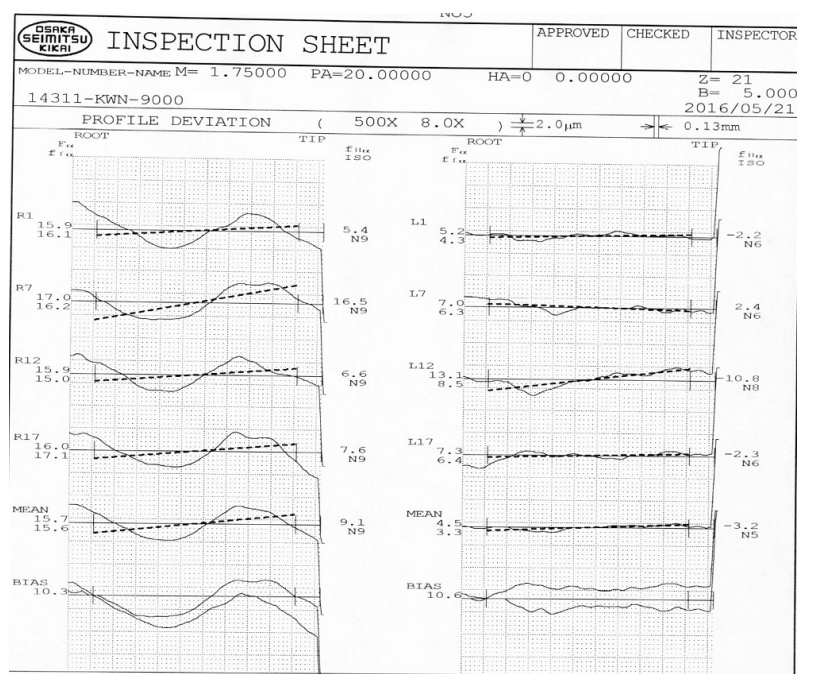

(b)

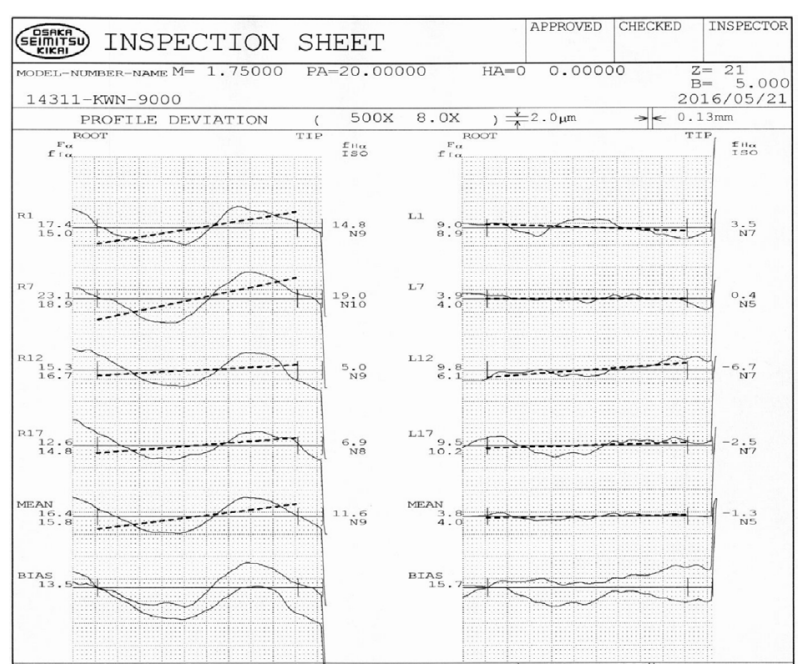

(d)

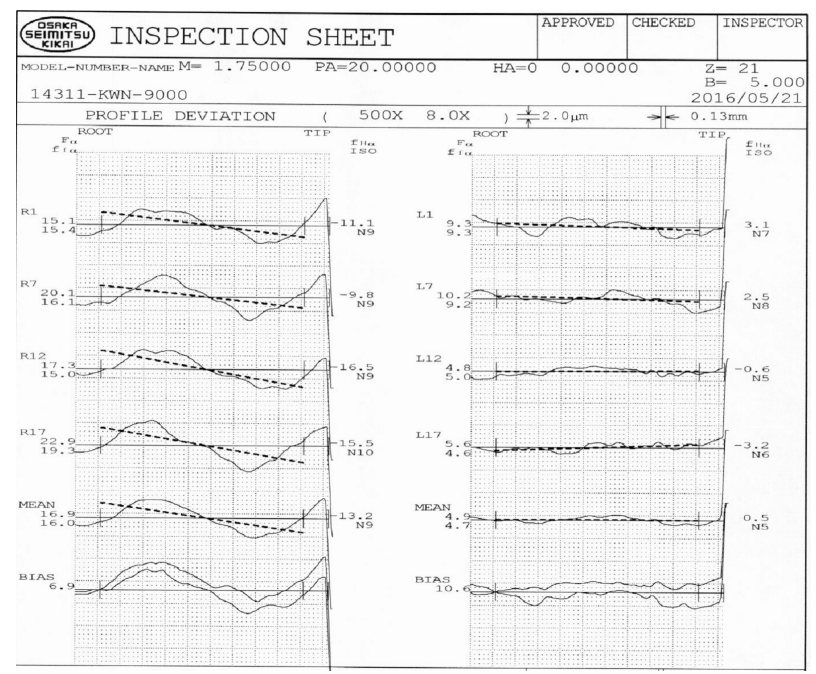

(f)

Figure 15. The profile error of the hobbed gears with nano lubricants. (a) The $50^{\text {th }}$ gear; (b) The $100^{\text {th }}$ gear; (c) The $200^{\text {th }}$ gear; (d) The $300^{\text {th }}$ gear; (e) The $400^{\text {th }}$ gear; (f) The $500^{\text {th }}$ gear. 
lubricant. The $\mathrm{Al}_{2} \mathrm{O}_{3}$ nanoparticles also effectively improve the heat transfer capability and create the "roller effect" which helps reduce the friction in cutting zone. The efficient lubrication features of nanoparticles in addition to their satisfactory cooling performance significantly lead to decrease hob wear, increase the tool life and enhance the gear profile accuracy and gear surface roughness. This study brings out not only such the promising solution for the existing gear production line but also many other applications in term of the engineering-economy effectiveness.

Further work of nano-cutting fluid in machining should include: undertaking more experimental work to enhance cutting performance results; investigating the nano concentration and the sizes and types of nano particles in cutting fluids to find out optimal parameters.

\section{Acknowledgements}

The authors acknowledge the device and financial support under Thai Nguyen University of Technology, Hanoi University of Science and Technology and Machinery Spare Parts No.1 Joint Stock Company (FUTU1), Vietnam.

\section{References}

[1] Sharma, A.K., Singh, R.K., Dixit, A.R. and Tiwari, A.K. (2015) Characterization and Experimental Investigation of $\mathrm{Al} 2 \mathrm{O} 3$ Nanoparticle Based Cutting Fluid in Turning of AISI 1040 Steel under Minimum Quantity Lubrication (MQL). Materials Today: Proceedings, 3, 1899-1906. https://doi.org/10.1016/j.matpr.2016.04.090

[2] Sayuti, M., Ahmed, A., Sarhan, D. and Hamdi, M. (2013) An Investigation of Optimum SiO2 Nanolubrication Parameters in End Milling of Aerospace Al6061-T6 Alloy. International Journal of Advanced Manufacturing Technology, 67, 833-849. https://doi.org/10.1007/s00170-012-4527-z

[3] Srikant, R.R., Rao, D.N., Subrahmanyam, M.S. and Krishna, V.P. (2009) Applicability of Cutting Fluids with Nanoparticle Inclusion as Coolants in Machining. Proceedings of the Institution of Mechanical Engineers, Part J, 223, 221-225. https://doi.org/10.1243/13506501JET463

[4] Rahmati, B., Ahmed, A., Sarhan, D. and Sayuti, M. (2014) Investigating the Optimum Molybdenum Disulf Ide (MoS2) Nanolubrication Parameters in CNC Milling of AL6061-T6 alloy. International Journal of Advanced Manufacturing Technology, 70, 1143-1155. https://doi.org/10.1007/s00170-013-5334-x

[5] Erh Ooi, M., Sayuti, M., Ahmed, A. and Sarhan, D. (2014) Fuzzy Logic-Based Approach to Investigate the Novel Uses of Nano Suspended Lubrication in Precise Machining of Aerospace AL Tempered Grade 60 61. Journal of Cleaner Production, 89, 286-295. https://doi.org/10.1016/j.jclepro.2014.11.006

[6] Eastman, J.A., Choi, U.S., Li, S., Thompson, L.J. and Lee, S. (1997) Enhanced Thermal Conductivity through the Development of Nanofluids. Materials Research Society Symposium Proceedings, 457, 3-11. https://doi.org/10.1557/PROC-457-3

[7] Khalilpourazary, S. and Meshkat, S.S. (2014) Investigation of the Effects of Alumina Nanoparticles on Spur Gear Surface Roughness and Hob Tool Wear in Hobbing process. International Journal of Advanced Manufacturing Technology, 71, 1599 1610. https://doi.org/10.1007/s00170-013-5591-8

[8] Ahmed, A., Sarhan, D., Sayuti, M. and Hamdi, M. (2012) Reduction of Power and 
Lubricant Oil Consumption in Milling Process Using a New SiO2 Nano Lubrication System. International Journal of Advanced Manufacturing Technology, 63, 505-512. https://doi.org/10.1007/s00170-012-3940-7

Submit or recommend next manuscript to SCIRP and we will provide best service for you:

Accepting pre-submission inquiries through Email, Facebook, LinkedIn, Twitter, etc. A wide selection of journals (inclusive of 9 subjects, more than 200 journals)

Providing 24-hour high-quality service

User-friendly online submission system

Fair and swift peer-review system

Efficient typesetting and proofreading procedure

Display of the result of downloads and visits, as well as the number of cited articles Maximum dissemination of your research work

Submit your manuscript at: http://papersubmission.scirp.org/

Or contactwjet@scirp.org 